\title{
SPESIES TUMBUHAN ASLI, INTRODUKSI DAN INVASIF DI PULAU BARRANGCADDI SULAWESI SELATAN
}

\author{
Native, Introduced And Invasive Plants In Barrangcaddi Island South Sulawesi
}

\author{
Dody Priosambodo ${ }^{1 *}$, Khairul Amri², Mahatma Lanuru ${ }^{2}$ \\ Diterima: 4 Juli 2019 Disetujui: 10 Juli 2019
}

\begin{abstract}
ABSTRAK
Penelitian tentang inventarisasi spesies tumbuhan di pulau Barrangcaddi yang berpenduduk padat telah dilakukan. Tujuan penelitian ini adalah untuk mengetahui jenis-jenis tumbuhan asli, tumbuhan introduksi dan tumbuhan invasif di Pulau Barrangcaddi. Kegiatan sampling dilakukan dengan metode purposive sampling. Data diambil dengan mencatat semua spesies tumbuhan yang ditemukan selama penjelajahan di pulau Barrangcaddi. Seluruh sampel di foto. Sampel tumbuhan yang tidak diketahui namanya, di ambil bagian-bagiannya, kemudian dikoleksi dan diidentifikasi di laboratorium Ilmu Lingkungan dan Kelautan, Departemen Biologi, Fakultas MIPA, Universitas Hasanuddin. Identifikasi sampel menggunakan buku: An Annotated Check-List of The Vascular Plants of The South China Sea and Its Shores oleh Turner et al. (2000) dan Mangrove Guidebook for Southeast Asia oleh Wim Giesen et al. (2007) untuk spesies hutan pantai; Tropical flowering plants: a guide to identification and cultivation oleh Kirsten Albrecht Llamas (2003) untuk spesies tanaman hias dan tanaman budidaya/introduksi serta Nonnative Invasive Plants of Pacific Coast Forest. A Field Guide for Identification oleh Gray et al. (2011) dan Guide to The Naturalized and Invasive Plants of Southeast Asia oleh Arne Witt (2017) untuk spesies tumbuhan invasif. Dari hasil penelitian di pulau Barrangcaddi tercatat sebanyak 142 spesies tumbuhan dari 51 suku. Sebagian besar didominasi oleh tanaman hias dan budidaya (introduksi) dengan 103 spesies dari 42 suku diikuti spesies asli (native species) dengan jumlah 29 spesies dari 19 suku. Spesies invasif tercatat paling sedikit dengan jumlah 10 spesies dari 5 suku. Sebagian besar tutupan vegetasi dari spesies asli telah hilang akibat alih fungsi lahan menjadi permukiman.
\end{abstract}

Kata Kunci: tumbuhan, asli, introduksi, invasif, barrangcaddi, pulau kecil, Kepulauan Spermonde

\begin{abstract}
Research about flora in very populated Barrangcaddi island has been conducted. The aim of this research was to make an inventory of native species, introduced species, invasive spesies of plant and also to investigate condition and status of vegetation in Barrangcaddi island. Sampling activities conducted with purposive sampling method. Data collected with noted the plant species that found during exploring the island. All sample are photographed. Unidentified sample were collected and identified in Marine and Environmental laboratory, Department of Biology, Faculty of Mathematics and Natural Sciences, Hasanuddin University. Identification of the sample conducted based on: An Annotated Check-List of The Vascular Plants of The South China Sea and Its Shores by Turner et al. (2000) and Mangrove Guidebook for Southeast Asia by Wim Giesen et al. (2007) for coastal forest species; Tropical flowering plants: a guide to identification and cultivation by Kirsten Albrecht Llamas (2003) for introduced species andNonnative Invasive Plants of Pacific Coast Forest. A Field Guide for Identification oleh Gray et al. (2011) and Guide to The Naturalized and Invasive Plants of Southeast Asia by Arne Witt (2017) for invasive species. Data were analysed descriptively and displayed in tabular form. Antropogenic impact i.e: land conversion and increased population were also discussed. From results of the study there were recorded 142 species of plants in Barrangcaddi Island. Mostly dominated by ornamental plants and cultivated (introduced) plants with 103 species from 42 families followed by native species with 29 species from 19 families. Invasive species were recorded with at least 10 species from 5 families. Most of native species has been extirpated due to land conversion for settlements.
\end{abstract}

Keywords: native, introduced, invasive, plants, barrangcaddi, small island, Spermonde archipelago

\section{PENDAHULUAN}

Indonesia termasuk salah satu negara yang memiliki banyak pulau-pulau kecil. Terjadinya perubahan iklim berdampak besar bagi kehidupan masyarakat pesisir di

\section{Korespondensi:}

Dody Priosambodo

E-mail: d.priosambodo@unhas.ac.id;

d.priosambodo@gmail.com

${ }^{1}$ Departemen Biologi, Universitas Hasanuddin

${ }^{2}$ Departemen Ilmu Kelautan, Universitas Hasanuddin pulau-pulau kecil. Permukaan air laut yang bertambah naik dan makin besarnya energi ombak memicu terjadinya abrasi pantai dan intrusi air laut. Pulau yang masih memiliki tutupan vegetasi asli di sepanjang garis pantai hingga ke tengah pulau umumnya memililki daya tahan (resilience) yang lebih baik. Sebaliknya, pulau yang telah kehilangan vegetasi aslinya akan lebih rentan terhadap dampak perubahan iklim. Salah satu pulau kecil di pesisir barat kota Makassar yang terkena imbas dari perubahan iklim adalah pulau Barrang Caddi. Dalam beberapa tahun terakhir, pulau ini terus mengalami abrasi dan intrusi air laut (Lanuru et al. 2018). 
Ekosistem pulau-pulau kecil dikenal miskin spesies florafauna dan sumberdaya alam serta rentan terhadap dampak perubahan lingkungan (Whittaker Fernandez-Palacios 2007). Pada kondisi alami, pulau-pulau kecil umumnya tertutup rapat oleh vegetasi semak, hutan pantai atau hutan bakau(Whittaker and Fernandez-Palacios 2007). Jenis tumbuhan didominasi oleh spesies yang bijinya dapat menyebar melalui air atau angin (Priosambodo dan Amri, 2014). Sebagian besar pulau-pulau kecil di Indonesia, seperti Kepulauan Spermonde di Sulawesi Selatan, kini telah kehilangan kawasan hutan pantainya akibat dampak antropogenik. Salah satu diantaranya adalah Pulau Barrangcaddi yang berpenduduk padat (Manez et al. 2012).

Hutan pantai mencakup seluruh bentang alam dan kelompok flora yang tumbuh mulai dari kawasan pantai hingga daerah pesisir. Hutan pantai umumnya ditemukan di pantai berpasir atau berbatu (Tuheteru dan Mahfudz 2012) dan mendapat genangan air laut beberapa kali dalam setahun (Giesen et al. 2007). Vegetasi pantai juga membentuk hutan yang rapat dengan ciri khas yang berbeda dengan hutan lainnya (Tuheteru dan Mahfudz 2012). Urutan zonasi hutan pantai sangat bervariasi dan berbeda-beda pada tiap-tiap daerah bergantung pada kondisi geomorfologi, topografi dan faktor lingkungan setempat (Giesen et al. 2007; Johns et al. 2012). Pada pantai berpasir yang landai dan luas dapat dijumpai zonasi yang dibentuk oleh herba menjalar, rumput dan semak (formasi pes-caprae) diikuti zonasi yang didominasi perdu dan pohon yang tumbuh rapat dan tinggi (formasi Barringtonia) (Goltenboth 2006; Whittaker dan Fernandez-Palacios 2007). Tumbuhan bakau yang umumnya hidup pada substrat berlumpur tidak termasuk dalam vegetasi pantai karena telah digolongkan dalam kelompok tersendiri yaitu: vegetasi mangrove (Giesen et al. 2007). Namun, jenis-jenis tumbuhan mangrove asosiasi juga sering ditemukan tumbuh di kawasan pantai dan pulau-pulau kecil (Whittaker Fernandez-Palacios 2007).

Hutan pantai umumnya ditemukan di pantai berpasir atau berbatu di daratan utama kontinental, pulau besar dan pulau-pulau kecil (Whittaker Fernandez-Palacios 2007). Pulau kecil didefinisikan sebagai pulau dengan luas daratan kurang dari $100 \mathrm{~km}^{2}$. Vegetasi pantai berperan penting sebagai penahan abrasi, mencegah intrusi air laut, memerangkap zat hara dan meningkatkan kandungan bahan organik dalam tanah serta menjadi produsen dalam jaring-jaring makanan sekaligus berperan sebagai habitat bagi berbagai jenis fauna (Tuheteru dan Mahfudz 2012).Vegetasi pantai juga berperan dalam menjaga ketersediaan air tawar yang menjadi kebutuhan vital bagi makhluk hidup (Manez et al. 2012). Hilangnya vegetasi pantai menjadikan pulau-pulau kecil semakin rentan terhadap ancaman dampak perubahan iklim global terutama oleh naiknya permukaaan air laut.
Perubahan iklim global diperkirakan akan menyebabkan naiknya level permukaan laut hingga $0,26 \mathrm{~m}-2,3 \mathrm{~m}$ pada tahun 2100. Hal ini akan berdampak pada makin besarnya arus dan gelombang di pantai, makin sering dan makin lamanya pulau-pulau kecil mengalami perendaman air laut dan meningkatnya erosi pantai (abrasi). Terendamnya pulau-pulau kecil akan menyebabkan matinya vegetasi darat yang tumbuh di pulau, musnahnya habitat dan hilangnya keanekaragaman hayati. Sedangkan abrasi menyebabkan semakin berkurangnya luas daratan hingga tenggelamnya pulau-pulau kecil (Courchamp et al. 2014).

Penelitian ini bertujuan untuk mengetahui jenis-jenis tumbuhan asli, tumbuhan introduksi dan tumbuhan invasif serta mencari informasi tentang status dan kondisi terkini dari vegetasi di Pulau Barrangcaddi. Dampak antropogenik berupa alih fungsi lahan untuk permukiman penduduk yang mempengaruhi kondisi vegetasi pantai di Pulau Barrangcaddi juga akan didiskusikan dalam tulisan ini.

\section{METODE PENELITIAN}

\section{Kondisi Umum Lokasi Penelitian}

Barrangcaddi termasuk pulau sangat kecil dengan jumlah penduduk yang padat. Pulau ini memiliki tutupan vegetasi yang sangat minim. Sebagian besar lahannya telah digunakan untuk permukiman. Area kosong hanyalah lapangan sepak bola, tempat pemakaman umum dan area di ujung selatan pulau yang menjadi lokasi pembuatan perahu. Topografi pulau tergolong landai dan datar dengan komposisi daratan terbentuk dari pasir dan endapan sedimen berkapur dari dasar laut yang telah mengalami proses pengangkatan secara geologis (Lanuru et al. 2018). Rataan terumbu yang luas dan dangkal terdapat di sisi barat, utara dan selatan. Sedangkan di sisi timur rataan terumbunya sempit dan curam. Perairan yang dalam di sisi timur ini digunakan sebagai tempat berlabuhnya kapal.

Pulau-pulau tak berpenghuni di Kepulauan Spermonde seperti pulau Podang-podang Caddi atau berpenduduk jarang seperti Kapoposang umumnya ditumbuhi vegetasi yang rimbun dan lebat menutupi hampir sebagian besar pulau (Priosambodo dan Amri, 2014). Pohon-pohon berukuran besar seperti: Kalumpang (Sterculia foetida) dan Beringin (Ficus sp.) umumnya masih dapat dijumpai. Pohon-pohon besar ini memiliki jaringan akar luas yang berperan penting dalam menyimpan dan menahan air di dalam tanah. Vegetasi pantai yang tumbuh rapat seperti pandan, beruas laut, jati pasir, kacang laut, rumput angin dan tapak kambing tumbuh rapat dan berperan dalam mengurangi energi ombak di sepanjang pantai sekaligus mencegah abrasi. Menurut Goltenboth et al. (2006), jenis-jenis tumbuhan penyusun vegetasi hutan pantai di pulau-pulau kecil wilayah tropis umumnya terdiri dari 
spesies-spesies serupa yang bijinya tersebar luas melalui angin atau air. Dengan demikian, pulau Barrangcaddi dulunya juga memiliki vegetasi yang tumbuh rapat menutupi seluruh permukaan pulau sebelum dihuni oleh banyak penduduk.

Meningkatnya jumlah penduduk menyebabkan kebutuhan akan lahan untuk permukiman meningkat. Akibatnya, vegetasi yang tumbuh secara alami semakin banyak dibabat. Pohon-pohon besar berusia puluhan tahun yang rawan tumbang saat musim pancaroba juga banyak ditebang karena lokasinya kini berada dekat dengan permukiman. Tumbuhan yang dikategorikan sebagai spesies asli pun menghilang dengan cepat. Penduduk di Kepulauan Spermonde umumnya akan membangun permukiman tidak jauh dari rumah orang tuanya. Terbatasnya lahan, membuat sebagian penduduk membabat habis vegetasi asli yang tumbuh di pantai, membuat pondasi dari batu karang dan menimbun pantai dengan pasir untuk membangun rumah baru. Dengan demikian, luas pulau bertambah, namun terumbu karang dan vegetasi pantai semakin menghilang.

Pada pulau yang ukurannya sedikit lebih besar seperti Sabutung, hilangnya spesies asli juga disebabkan oleh alih fungsi lahan menjadi kebun (Priosambodo, 2018). Hutan pantai yang berada di bagian tengah pulau pun ditebang sedikit demi sedikit. Tanah bekas hutan yang memiliki sedikit lapisan humus ini kemudian ditanami pisang, ubi kayu, ubi jalar dan jenis tanaman budidaya lainnya. Pola tanam tanpa pemupukan ini menyebabkan lapisan humus semakin menghilang. Kualitas tanah terus menurun hingga tak dapat ditanami lagi. Akibatnya dalam beberapa tahun, kebun yang telah dibuka kemudian ditinggalkan karena tanaman tidak dapat tumbuh dengan baik. Area kebun yang tak terurus ini kemudian ditumbuhi oleh rumput dan semak seperti: alang-alang, lamtoro, kirinyu, bunga tai ayam dan jarong (Priosambodo, 2018). Menurut Witt (2017), rumput dan semak yang mampu tumbuh di lahan marginal tergolong spesies invasif.

Terbatasnya akses dan sumberdaya membuat pemenuhan kebutuhan rumah tangga sehari-hari di pulau-pulau kecil lebih sulit dibandingkan dengan pulau-pulau besar dan perkotaan. Untuk mengatasi hal tersebut, sebagian penduduk pulau Barrangcaddi memanfaatkan lahan pekarangan di sekitar rumah dengan menanam berbagai jenis tanaman budidaya yang dapat dikonsumsi seharihari, seperti: kelor, lombok kecil, tomat, terong, ubi kayu, ubi jalar, pisang, jeruk nipis, srikaya, sirsak, serai, mangga dan lain-lain. Untuk meningkatkan kenyamanan dan menciptakan kawasan permukiman yang hijau dan asri, pemerintah melalui ajang lomba desa dan program ibu-ibu PKK mewajibkan penduduk setempat untuk melakukan penghijauan dengan menanam tanaman hias dan tanaman peneduh di sekitar pekarangan rumah dan tepi jalan. Akibatnya, spesies introduksi di pulau Barrangcaddi pun meningkat secara drastis. Menurut Witt (2017), tanaman hias dan pekarangan tergolong spesies introduksi.

\section{METODE PENELITIAN}

Penelitian dilakukan menggunakan metode purposive sampling dengan menjelajahi daratan pulau Barrangcaddi dan mencatat spesies tumbuhan asli, tumbuhan invasif dan tumbuhan introduksi yang ditemukan.Pengambilan foto habitus dan bagian tumbuhan (jika memungkinkan) dilakukan pada sampel yang ditemukan.Sampel yang belum diketahui namanya kemudian diambil untuk diidentifikasi lebih lanjut di laboratorium Ilmu Lingkungan dan Kelautan, Departemen Biologi FMIPA Universitas Hasanuddin.Beberapa referensi acuan yang digunakan untukmengidentifikasi sampeladalah:An Annotated Check-List of The Vascular Plants of The South China Sea and Its Shores oleh Turner et al. (2000) dan Mangrove Guidebook for Southeast Asia olehWim Giesen et al. (2007)untuk spesies hutan pantai;Tropical flowering plants: a guide to identification and cultivation oleh Kirsten Albrecht Llamas (2003) untuk spesies tanaman hias dan tanaman budidaya introduksi sertaNonnative Invasive Plants of Pacific Coast Forest. A Field Guide for Identification oleh Gray et al. (2011) danGuide to The Naturalized and Invasive Plants of Southeast Asia oleh Arne Witt (2017) untuk spesies tumbuhan invasif.

\section{Waktu dan Lokasi sampling}

Pengamatan vegetasi pantai di pulau Barrangcaddi dilakukan pada bulan Oktober 2017. Secara administratif, pulau Barrangcaddi masuk dalam wilayah Kecamatan Sangkarrang, Kota Makassar, Sulawesi Selatan.

\section{Analisis Data}

Analisis data dilakukan secara deskriptif terhadap jenis tumbuhan asli, tumbuhan introduksi dan spesies invasif yang berhasil diamati. Pengelompokan kategori spesies tumbuhan di Pulau Barrangcaddi menjadi spesies asli, introduksi dan invasif dilakukan berdasarkan beberapa referensi acuan yang telah uraikan di bagian metode penelitian. Hasil analisis data disajikan dalam bentuk tabel.

\section{HASIL DAN PEMBAHASAN}

Dari hasil pengamatan, identifikasi dan analisis data, tercatat total jumlah spesies tumbuhan yang ditemukan di Pulau Barrangcaddi sebanyak 142 spesies dari 51 suku, mencakup: 29 spesies tumbuhan asli dari 34 suku, 103 spesies tanaman hias dan budidaya (introduksi) dari 46 
suku serta 10 jenis tumbuhan invasif dari 5 suku. Adapun daftar jenis tumbuhan dari masing-masing kategori dapat dilihat di bagian lampiran.

Komposisi spesies dan suku dari tiga kategori tumbuhan (spesies asli, introduksi dan invasif) yang ada di Pulau Barrangcaddi menunjukkan perbedaan (Tabel 1). Jenis tumbuhan asli didominasi oleh Poaceae (rumputrumputan) dan Fabaceae (polong-polongan). Spesies introduksi banyak berasal dari suku Araceae (talastalasan), Euphorbiaceae (jarak-jarakan), Acanthaceae (Jeruju-jerujuan) dan Arecaceae atau Palmae (Palem- paleman). Sedangkan spesies invasif didominasi oleh suku Asteraceae (seruni-serunian).

Vegetasi pantai yang masih alami dan tak terganggu umumnya membentuk pola yang khas. Pada daerah pantai berpasir yang landai dan luas di atas air pasang rata-rata, umumnya ditumbuhi herba menjalar yang tumbuh rapat menutupi pasir pantai. Setelah herba, vegetasi berikutnya adalah semak yang tumbuh dalam zonasi sempit dan memanjang mengikuti garis pantai diikuti perdu dan pohon.

Tabel 1. Perbandingan komposisi jenis tumbuhan dari delapan suku dengan jumlah spesies terbanyak untuk kategori spesies asli, introduksi dan invasif di pulau Barrangcaddi.

\begin{tabular}{|c|c|c|c|c|c|c|}
\hline \multirow[b]{2}{*}{ No } & \multicolumn{2}{|l|}{ Spesies Asli } & \multicolumn{2}{|c|}{ Spesies Introduksi } & \multicolumn{2}{|l|}{ Spesies Invasif } \\
\hline & Suku & $\begin{array}{l}\text { Jumlah } \\
\text { Spesies } \\
\end{array}$ & Suku & $\begin{array}{l}\text { Jumlah } \\
\text { Spesies } \\
\end{array}$ & Suku & $\begin{array}{l}\text { Jumlah } \\
\text { Spesies }\end{array}$ \\
\hline 1 & Poaceae & 4 & Araceae & 10 & Asteraceae & 3 \\
\hline 2 & Fabaceae & 3 & Euphorbiaceae & 10 & Fabaceae & 2 \\
\hline 3 & Amaryllidaceae & 2 & Acanthaceae & 8 & Poaceae & 2 \\
\hline 4 & Asteraceae & 2 & Arecaceae & 8 & Verbenaceae & 2 \\
\hline 5 & Boraginaceae & 2 & Asparagaceae & 5 & Euphorbiaceae & 1 \\
\hline 6 & Malvaceae & 2 & Amaryllidaceae & 3 & & \\
\hline 7 & Rubiaceae & 2 & Apocynaceae & 3 & & \\
\hline 8 & Amaranthaceae & 1 & Lamiaceae & 3 & & \\
\hline 9 & Combretaceae & 1 & Malvaceae & 3 & & \\
\hline 10 & Convolvulaceae & 1 & Nyctaginaceae & 3 & & \\
\hline
\end{tabular}

Vegetasi yang tumbuh di sepanjang pantai berpasir pulaupulau kecil di Indonesia terdiri dari jenis herba merambat dan rumput-rumputan, seperti: katang-katang Ipomoea pes-caprae (Convolvulaceae), krokot Sesuvium portulacastrum (Aizoaceae), kacang laut Canavalia maritima dan Vigna marina (Fabaceae), rumputrumputan dari jenis Ischaemum muticum, Fimbristylis sericea, Remirea maritima, Spinifex littoreus (Poaceae). Kelompok herba ini umumnya dikenal sebagai formasi pes-caprae. Bergeser ke garis pasang tertinggi, dominasi herba digantikan oleh vegetasi semak seperti: santigi Pemphis acidula (Lythraceae), beruas laut Scaevola taccada (Goodeniaceae), Tournefortia argentea (Boraginaceae), jati pasir Guettarda speciosa (Rubiaceae), buas-buas Premna corymbosa (Lamiaceae), daun tiga Dendrolobium umbellatum (Fabaceae), seruni Wedelia biflora (Asteraceae), dan tumbuhan parasit tali putri Cassytha filiformis (Lauraceae).

Vegetasi semak di pantai-pantai Indonesia umumnya tumbuh dalam area yang sempit mengikuti garis pantai dan segera digantikan kelompok perdu dan pohon. Beberapa jenis perdu dan pohon yang sering ditemukan adalah: Pandan pantai Pandanus tectorius (Pandanaceae),
Ketapang Terminalia catappa (Combretaceae), Malapari Pongamia pinnata(Fabaceae), waru Hibiscus tiliaceus (Malvaceae), waru laut Tesphesia populnea (Malvaceae), putat Barringtonia asiatica (Lecythidaceae), Punaga Calophyllum inophyllum (Calophyllaceae), mengkudu Morinda citrifolia (Rubiaceae), cemara laut Casuarina equisetifolia (Casuarinaceae) dan kelapa Cocos nucifera (Arecaceae). Tegakan campuran dari berbagai jenis pohon ini dikenal sebagai formasi Barringtonia. Bersama dengan formasi pes-caprae, formasi Barringtonia membentuk hutan pantai di pulau-pulau kecil Indonesia (Brown et al. 1998; Goltenbothet al. 2006; Giesen et al. 2007; Whittaker et al 2007; Johns et al. 2012).

Pembabatan hutan pantai untuk permukiman berdampak buruk bagi ekosistem pulau Barrangcaddi. Hutan pantai memiliki peran vital dalam menjaga dan mempertahankan kandungan air dalam tanah. Hutan pantai yang tumbuh rapat dan tinggi dapat menciptakan iklim mikro yang menjaga suhu tanah tetap stabil. Jalinan akar yang kompleks dan serasah daun di dasar hutan dapat berperan sebagai penahan dan penyimpan air.

Menurut Undang-Undang RI No.27 Tahun 2007, pulau kecil didefinisikan sebagai pulau yang berukuran luas 
kurang atau sama dengan $2000 \mathrm{~km}^{2}$ atau sekitar $50 \mathrm{x} 40$ km. Manez et al. (2012), menambahkan bahwa pulau "sangat kecil" (100 km²atau 10 x10 km) umumnya tidak memiliki sumber air tawar permukaan seperti sungai atau danau. Sumber utama air tawar di pulau kecil adalah air tanah dan air hujan. Air tawar dalam tanah di pulau-pulau kecil umumnya berada di dekat permukaan tanah berpasir putih (coral sand) atau batu kapur (limestone). Kumpulan air ini berada dalam suatu "kantong" berbentuk cembung seperti lensa tipis yang mengapung di atas air asin yang lebih berat di dalam tanah.

Lambs et al. (2015), menyatakan bahwa hilangnya hutan pantai dapat menyebabkan berkurangnya kandungan air tawar dalam tanah akibat penguapan (evaporasi), meningkatnya resiko intrusi air laut dan meningkatnya salinitas tanah. Nurse et al. (2014) menambahkan, naiknya salinitas air dan tanah berakibat pada matinya spesies tumbuhan yang kurang toleran terhadap kadar garam tinggi. Berkurangnya tumbuhan akan mengganggu jaring-jaring makanan, menghancurkan habitat dan menurunkan keragaman hayati.

Hasil pengamatan secara visual menunjukkan bahwa sebagian besar vegetasi formasi pes-caprae, semak pantai dan pohon-pohon besar telah hilang dari pantai pulau Barrangcaddi. Vegetasi di sekitar permukiman kini lebih banyak didominasi spesies introduksi yang ditanam di pot-pot dan tepi jalan. Meskipun pohon-pohon dari spesies introduksi dapat tumbuh dengan baik, namun keberadaan tanaman hias ini tidak dapat menggantikan peran spesies asli dalam ekosistem pulau-pulau kecil yang rapuh. Spesies introduksi tidak menghasilkan serasah dalam jumlah besar yang dapat mengurangi laju evaporasi, meningkatkan kandungan zat hara dalam tanah dan mendukung kehidupan hewan liar setempat.

Meningkatnya populasi penduduk berbanding lurus dengan meningkatnya konsumsi air tawar (Tatas et al. 2015). Dalam ekosistem pulau-pulau kecil, air tawar menjadi faktor pembatas dan sumberdaya alam yang berharga baik bagi manusia maupun berbagai jenis flora fauna (Alberti et al. 2017). Populasi penduduk yang terlalu padat di pulau-pulau kecil dapat menyebabkan berkurangnya persediaan air tanah. Manez et al.(2014), melaporkan bahwa beberapa pulau di Kepulauan Spermonde seperti Pulau Badi (kepadatan populasi 216257 jiwa/Ha), Barrang Caddi (kepadatan populasi 325 jiwa/Ha), Bone Tambung (kepadatan populasi 96 jiwa/Ha) dan Saugi (kepadatan populasi 274 jiwa/Ha) telah mengalami kelangkaan air akibat populasi penduduk berlebih. Air tawar di Pulau Barranglompo juga dilaporkan berubah rasa menjadi semakin payau dalam beberapa tahun terakhir (personal observation).
Selain itu, populasi penduduk yang berlebihan beresiko mencemari sumber air jika fasilitas penampungan dan pembuangan limbah dari aktifitas mandi, cuci dan kakus(MCK) tidak dikelola dengan baik (Alberti et al. 2017). Nurse et al. (2014) menambahkan bahwa berkurangnya air tanah di pulau-pulau kecil dapat memicu intrusi air laut yang menyebabkan sumber air di daratan pulau menjadi payau/asin.

Pulau-pulau kecil termasuk salah satu area yang akan mengalami dampak paling mematikan dari perubahan iklim. Naiknya suhu air laut menyebabkan pemutihan pada jaringan lunak terumbu karang. Akibatnya, terumbu karang mati dan tidak dapat melindungi pantai dari hempasan gelombang. Naiknya rata-rata permukaan air laut dan besarnya gelombang akan menggerus tepi pantai, menumbangkan semak, perdu, pohon-pohondan mengurangi luas pulau. Penggenangan daratan pulau oleh air laut menyebabkan kadar garam di permukaan dan dalam tanah meningkat. Vegetasi di daratan pulau pun tidak mampu tumbuh akibat sering tergenang air laut. Akhirnya, pulau-pulau kecil akan tenggelam (Courchampet al. 2014; Nurse et al.2014; Lambs et al.2015; Alberti et al. 2017).

\section{KESIMPULAN}

Dari hasil pengamatan, identifikasi dan analisis data, tercatat total jumlah spesies tumbuhan yang ditemukan di Pulau Barrangcaddi sebanyak 142 spesies dari 51 suku, mencakup: 29 spesies tumbuhan asli dari 34 suku, 103 spesies tanaman hias dan budidaya (introduksi) dari 46 suku serta 10 jenis tumbuhan invasif dari 5 suku. Populasi penduduk yang berlebih dan alih fungsi lahan menjadi permukiman menyebabkan hilangnya sebagian besar spesies tumbuhan asli di Pulau Barrangcaddi. Hal ini menyebabkan pulau Barrangcaddi mengalami tekanan ekosistem yang berat sehingga rentan terhadap dampak perubahan iklim seperti abrasi pantai dan intrusi air laut.

\section{DAFTAR PUSTAKA}

Alberti L, IL Licata and M Cantone 2017. Saltwater Intrusion and Freshwater Storage in SandSediments along the Coastline: Hydrogeological Investigations and Groundwater Modelling of Nauru Island. Water 2017 (9)788: 121.

Brown, JH and MV Lomolino 1998. Biogeography. Second Edition.Sinauer Associates, Inc. Publisher.Masshacusetts. USA. 692 pp + xii.

Church, JA, NJ White and JR Hunter 2006. Sea-level rise at tropical Pacific and Indian Ocean Islands. Global and Planetary Change 53 (2006): 155-168. 
Courchamp, F, BD Hoffmann, JC Russel, C Leclerc and C Bellard 2014. Climate change, sea-level rise, and conservation: keeping island biodiversity afloat. Forum.Trends in Ecology and Evolution. March 2014. Vol. 29. No. 3: 127-130.

Giesen, W, S Wulffraat, M Zieren and L Scholten 2007, Mangrove Guidebook for Southeast Asia. RAP Publication 2006/2007, FAO and Wetlands International, $574 \mathrm{pp}+$ xii.

Goltenboth, F, KH Timotius, PP Milan and J Margraf 2006. Ecology of Insular Southeast Asia-The Indonesian Archipelago. Elsevier. Amsterdam.557 pp+x.

Gray, AN, K Barndt and SH Reichard 2011. Nonnative Invasive Plants of Pacific Coast Forest. A Field Guide for Identification.United States Department of Agriculture (USDA).

Johns, RJ, GA Shea and P Puradyatmika 2012. Chapter 5.6. Coastal Vegetation of Papua in: Marshall, AJ and Bruce M Beehler (Eds) 2012. The Ecology of Papua. Part II. Tuttle Publishing. Page: 901-909.

Lanuru, M, W Samad, K Amri and D Priosambodo 2018. Oceanographic Conditions and Sediment Dinamic of The Barrang Caddi Island (Spermonde Archipelago, Indonesia). IOP Conf. Ser.: Earth Environ. Sci. 157012040.

Lambs L, F Bompy, D Imbert, D Corenblit and M Dulormne 2015. Seawater and Freshwater Circulations through Coastal Forested Wetlands on a Caribbean Island. Water.(2015) 7: 41084128.

Manez, KS, S Husain, SCA Ferse and MM Costa. 2012. Water scarcity in the Spermonde Archipelago, Sulawesi, Indonesia: Past, present and future. Envireonmental Science and Policy. 23 (2012): 74-84.

Nurse, LA, RF McLean, J Agard, LP Briguglio, V DuvatMagnan, N Pelesikoti, E Tompkins, and A Webb 2014:Small islands. In: Climate change 2014: Impact, adaptations and vulnerability. Part B:
Regional Aspect contribution of Working Group II to the Fifth Assesment Report of The Intergovernmental panel on Climate Change [Barros, VR, CB Field, DJ Dokken, MD Mastrandrea, KJ Mach, TE Bilir, M Chatterjee, KL Ebi, YO Estrada, RC Genova, B Girma, ES Kissel, AN Levy, S MacCracken, PR Mastrandrea and LL White (eds.)]. Cambridge University Press, Cambridge, United Kingdom and New York, NY, USA, pp. 1613-1654.

Priosambodo, D and K Amri 2014. Distribution of coastal vegetation in Kapoposang Marine Tourism Park South Sulawesi. Proceeding of international and national conference on marine science and fisheries.Climate change, marine life and lifelihoods in the center of coral triangle. Makassar, September $10^{\text {th }}-11^{\text {th }}, 2013$. ISBN 978602-8405-53-9.

Priosambodo, D 2018. Vegetasi Hutan Pantai Pulau Sabutung Sulawesi Selatan. Jurnal Ilmu Alam dan Lingkungan 9 (17) (2018) 19 - 30.

Tatas AB, Khoiri M, Lestari W and Rahman A 2015. Study on water balance in Poteran- a small island in East Java, Indonesia. The 5th International Conference of Euro Asia Civil Engineering Forum (EACEF-5). Procedia Engineering 125 ( 2015 ) $236-242$.

Tuheteru, FD dan Mahfudz 2012. Ekologi, Manfaat dan Rehabilitasi Hutan Pantai Indonesia. Balai Penelitian Kehutanan Manado.178 pp + X.

Turner IM, Fuwu X and Corlett, RT 2000. An Annotated Check-List of The Vascular Plants of The South China Sea and Its Shores. The Raffles Bulletin of Zoology. Supplement No.8: 23-116. National University of Singapore.

Whittaker, RJ and Fernandez-Palacios, JM 2007. Island Biogeography. Second edition. Oxford University Press Inc. New York. 401 pp + xii.

Witt, A 2017. Guide to The Naturalized and Invasif Plants of Southeast Asia. CAB International. Oxfordshire. United Kingdom. 207 pp + vi. 